International Journal of Engineering \& Technology, $7(2.7)(2018) 422-427$
International Journal of Engineering \& Technology
Website: www.sciencepubco.com/index.php/IJET
Research Paper

\title{
Internet of things and its applications
}

\author{
Y. Shanmukha Sai ${ }^{1}$ *, K. Kiran Kumar ${ }^{2}$ \\ ${ }^{1}$ Research Scholar, Department of Computer Science \& Engineering, Koneru Lakshmaiah Education Foundation, Guntur Dt., A.P. \\ ${ }^{2}$ Professor, Department of Electronics \& Computer Science Engineering, Koneru Lakshmaiah Education Foundation, Guntur Dt., A.P \\ *Corresponding authorE-mail: shanmukhasaiy@gmail.com
}

\begin{abstract}
IOT is creating impeccable things by improving the performance of system in the field of communications in many technical applications in expedite manner and taken the system performance to next level. implementing IOT in today's world out do's the response time of the system to the normal system response in R\&D applications. this paper depicts the challenges and the problems in various domains and gave the solution by imbibing IOT Technology by standardizing the system processes to meet the industrial as well as domestic needs.
\end{abstract}

Keywords: ANN Technology; Aurdino Boards; Internet of Things; Raspberry pi Boards; Sensors.

\section{Green house farming}

Day-by-day increase of temperature on the surface of earth due to the adverse effects of pollution and global warming leads to rise in the radiation of earth's atmospheric conditions. This leads to rise in temperature on earth because of rise in radiation level by greenhouse gases i.e., $\mathrm{CO} 2$, Methane, Nitrous Oxide and Fluorinated gases. These Green House Gases in the atmosphere absorb the heat and redirect back that heat towards the earth surface. These greenhouse gases keep the surface warm on winter days and thus makes farming much easier. So we make use of this greenhouse effect in Green House Farming.

Green house farming technology has been implementing by many developed countries. This technology has been now adopting by many developing countries including India, due to better yielding efficiency and quality in farming. In green house farming technology, it uses translucent materials. These translucent materials permit the light to pass through it by diffusing principle so that the objects, things and persons on the other end were not clearly visible. So these translucent materials were used in growing vegetables, fruits, and flower crops under the controlled climatic conditions. This technology gives high yielding with high quality crops to meet the market demands within the limited land resources. This gives the advantage of evolution of new varieties of its kind and innumerous seed productions. The green houses technology is widely based on covering material, shapes and structure of the farming type, environment control strategies with nominal budget. Green House Farming by using IOT and cloud computing is the present trend going on all over the world[1]. There are many techniques for precision agriculture to monitor and control the environment for better growth of crops. The main hurdle is unequal distribution of rain water in India. So this inequalities leads to unequal distribution of water throughout the cultivation season[2]. Green house farming technology is the best solution to control and manage the problem.

\section{Medical applications}

In today's world most of the diseases are contiguous. They were listed out in 37 different types.

Numerous methods were adopted and implemented in medical field to reduce the growth of bacterial diseases. There is a lack of awareness among the people all over the world in hygiene point. In combination of wireless sensor network's and IOT technologies a monitoring system has been developed for hand hygiene compliance rate. This hand hygiene stations were connected through cloud to detect the hygiene perspective at all instance of time[3]. A set of wireless components have been employed depending on IEEE 802.15.4 and 802.11 token ring protocols with RFID. This gives the best scalability and flexibility to the system. A clientserver software architecture was designed to monitor individual hand hygiene compliance.

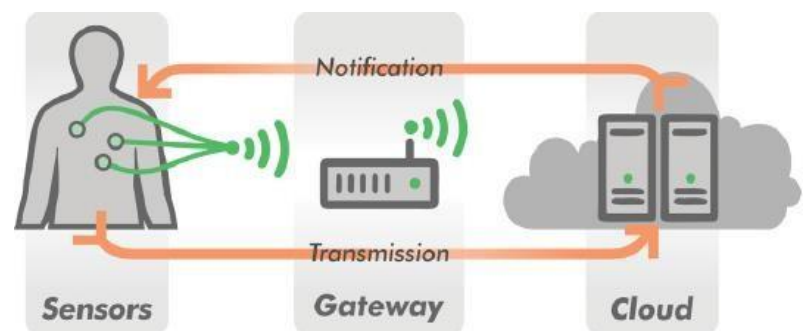

Fig. 1: A View of the IOT-Based System for Remote Patient Monitoring.

People who are suffering with acute diseases mostly because of abrupt heart conditions requires continuous monitoring. It is not possible to monitor continuously alongside of patient. Hence remote patient monitoring is developed. Continuous health monitoring will provide current medical state of the patient such that it can predict the critical situations. A new IOT based approach for personalized patient monitoring has been explained and shown in figure 1[4].

Machine learning algorithms have been employed to automate management of system components in computing section. Rasp- 
berry pie zero and Jetson_TK1 were deployed in machine learning algorithms, support vector machines (SVM), K-nearest neighbour algorithms were used for analysing and plan computing components. The decision making data that was obtained from the above supervised learning algorithms were adopted in datasets in plan components.

Phonocardiogram is the device which generates phonocardiograph (PCG) through sounds and murmurs by the heart. Depending upon the PCG value, a graph is generated. This is transmitted to communication gateway channel, here Arduino (AT mega 328P) and Raspberry pi3 were used for managing and processing the data as shown in figure 2 . This data is transmitted to data centres through internet. This data is accessible to N-number of users throughout the world by proper authentication. The local access can be provided through a private key from indigenously developed middleware architecture[5].

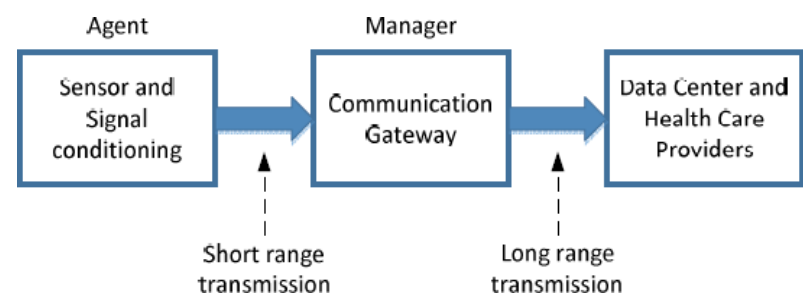

Fig. 2: Typical IMEDT for Cardiac Monitoring System.

Hence by conjugating the data with IOT a continuous patient health monitoring is performed.

A wireless communication is made between by medical device and a light control system. An application has been developed to control the on and off switching of lights for disabled person. A Bluetooth, touch panel over Arduino board is connected using auto desk circuit software and controlling is obtained through a mobile phone[6].

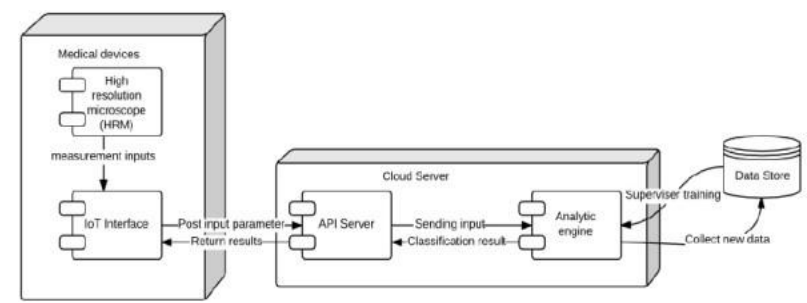

Fig. 3: Component Diagram of the Centralized Cervical Cancer Diagnosis System with IOT

A server-client model system has been developed using Internet of Things (IOT) and Artificial Neural Networks (ANN) by employing high resolution microscopes which classifies the images for Pap smear test. 84 images from high resolution microscope has been fed to server through IOT. The server is loaded with 834 different images of Pap smear test. Back propagation algorithm differentiates and compares the 84 Pap smear images into two divisions (42 each). ANN gives the appropriate result. Using Raspberry PI module this Pap test has been performed as depicted in figures 3 and 4 [7].

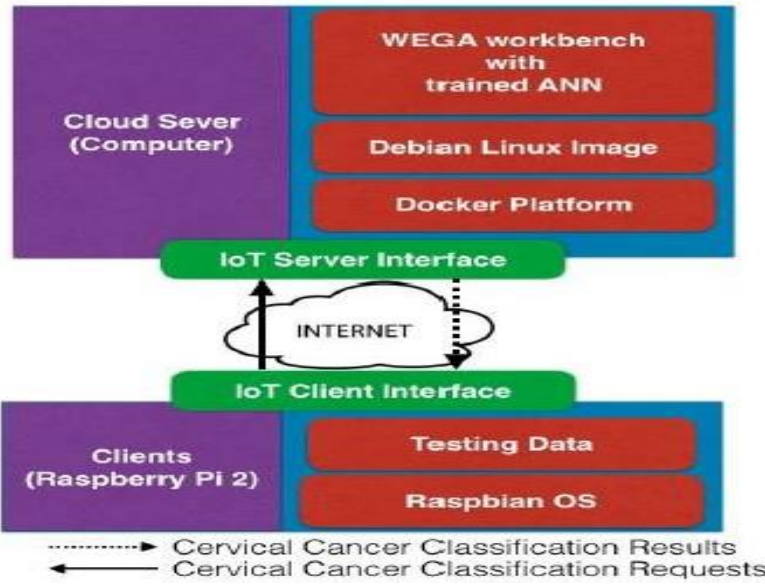

Fig. 4: Simulation of Centralized Cervical Diagnosis System.

\section{Image processing applications}

System on Chip-Field Programmable Gate Array interface is designed to provide access for remote image processing. IOT enhances off-site processing systems for accessing multiple nodes through its eco-system. The images were being processed and scaled using web filtering tools. This gives advantage of scaling up for larger images [8] [9].Transmission of huge video data into the cloud has been performed using remote IOT server to progress the process smoothly [10].

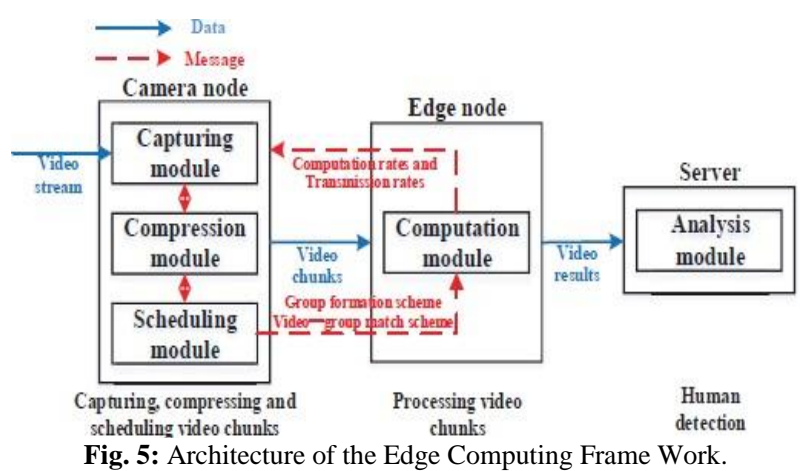

An end-to-end IOT edge cloud system for image processing and analytics which enables the monitoring of wild life in remote locations automatically has been developed as shown in figure 5 [11] The system is customized and uses camera pictures which contains images of bear, dear, etc., IOT system connects all the motion triggered cameras with the help of Wi-Fi through a distributed system. Artificial Neural Networks have been employed for recognition of variety of animals in the images from the cloud as shown in figure 6.

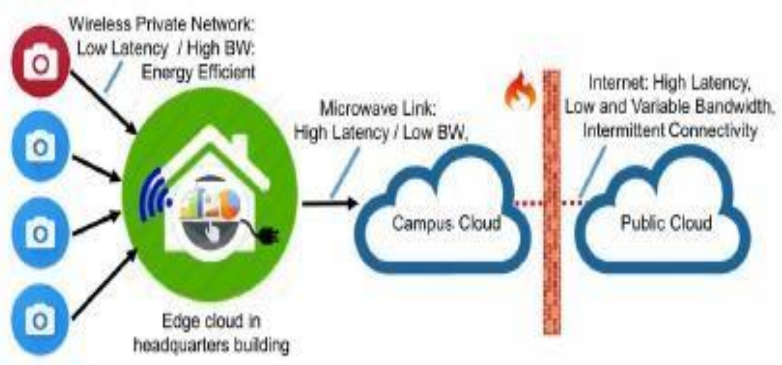

Fig. 6: The WTB System.

IOT based smart museum was developed using Raspberry PI which will be captured by the user. Later on image processing is performed and localization information is obtained through Bluetooth Low Energy (BLE) which is deployed in the museum. This enables the user to take a picture, match the frames in cloud pro- 
cessing centre. Thus everyone has an easy access and profile history about the image is obtained through smart phone[12].

\section{Traffic and tracking application}

A smart umbrella has designed which navigates the person during heavy rain and fog which provides a better navigation to the destination using smart phone based IOT environment [13].

A smart traffic management system has been developed for better transportation as shown in figure 7 [14]. A low cost vehicle detecting sensors were deployed in the middle of the road for every 500 meters and data were acquired quickly. By sending the latest data to IOT, the real time traffic streaming data is transmitted for big data analytics where several analytical scriptures were used to analyse the traffic density and provide solution through predictive analysis. This data has been mugged to a mobile app which provides the traffic rate at various places and navigates an alternative way by managing the traffic [15] [16].

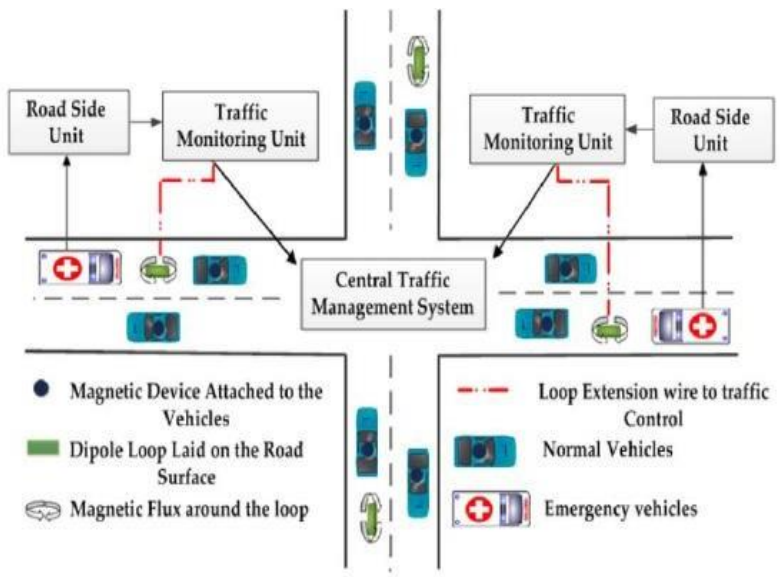

Fig. 7: Smart Central Wise Traffic Management System.

A passive chip less RFID multi-resonator based tag structure is developed for tracking the traffic continuously in the real time environment[17]. This tag is of triangular structure in which each triangle is loaded with open slots. Every resonator deals with a notch at a particular frequency that gives 7-bits for 7 resonators. This tags were optimized and analysed for three different substrates for sensing applications.

\section{Air pollution monitoring}

Heterogeneous data and the data from crowd sensing has been integrated by Sen square architecture[18]. It produces valuable services to the people from the real time data gathered through crowd sensing. Data can be customized by the user himself with the help of IOT.

A low cost air pollution monitoring device has been developed for monitoring and calculating the amount of air pollution in the atmosphere in a particular area[19]. Five sensors namely ozone sensor MQ 131,carbon monoxide sensor MQ7,pm sensor, Temperature and humidity sensor DHT 22,ultra violet sensor GUVA were connected to a microprocessor[20]. A Wi-Fi system has been employed for controlling operations such as data acquisition and uploading of data into cloud. This data was collected from the sensor and is stored into the cloud. Such that access has been provided for the user about the air pollution information in the atmosphere around the surroundings.

Air pollution is measured using TGS 2600 sensor which senses the concentration of various gases. MiCS-2714 sensor is used for measurement of $\mathrm{NO} 2$ in the atmosphere and MiC-5134 foe CO. The data was fetched into big sensor data server and can be retrieved through Wi-Fi services which were enabled by ideal clean Wi-Fi concept [21].
Temperature, humidity and dust has been detected and calculated and data is transmitted by ZigBee network through yeelink internet platform into the cloud by the figure 8 [22] [23]. The users can monitor the real time data using internet.

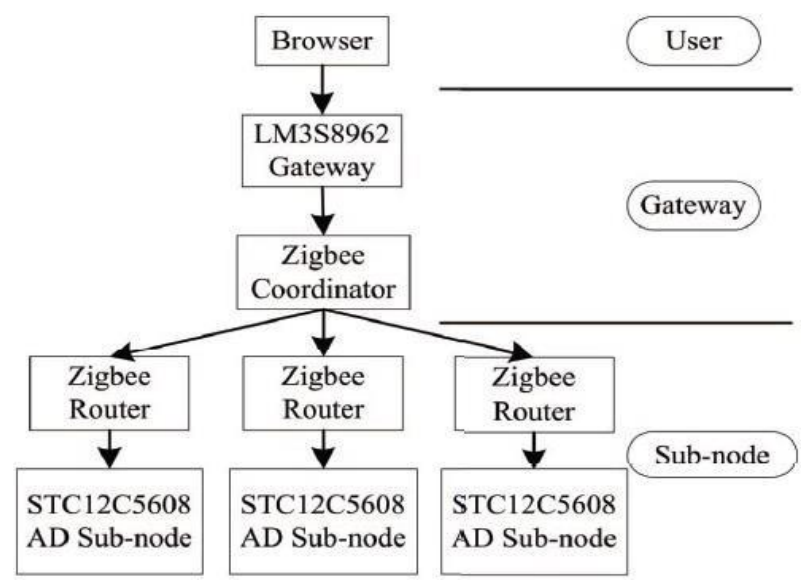

Fig. 8: System Structure Design.

Air pollution measurement and prediction system has been developed using Microsoft's Azure machine learning process. The data is stored in the cloud and can be accessed to take necessary preventive measures [24].

Vehicular pollution measurement is done by RFID readers deployed at junctions of the road. Gas sensors were also employed at the road side to collect the data of air pollution caused by vehicles. RFID tags were fitted to vehicles which regularly pass through the junctions. The data from the RFID reader tags measures the pollution level from individual vehicles across all points of time and is fetched to cloud. The data is retrieved back and calibration can be done [25] [26].

\section{Water management and monitoring}

Water monitoring system enabled IOT technology is the best kind of managing water level system in the today's world. The variety kinds of ultraviolet sensors were employed to detect the water level in every instance of time as shown in figure 9. This proximity kind of sensors give accurate results without any discrepancy [27] [28] [29] [30]. The output from the ultraviolet sensor is fed to the server through internet and can be accessed by the user for monitoring the water level system real time.

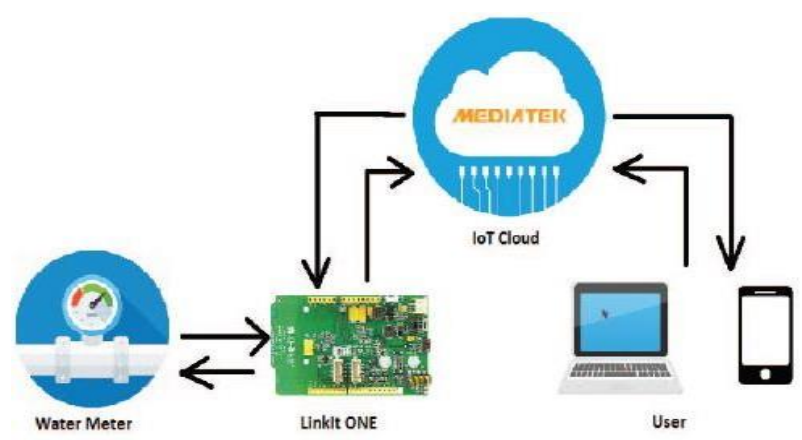

Fig. 9: Iot Based Water Meter.

A system for reliable smart water distribution metering has been developed using IOT technology[31]. The system is developed in standalone manner such that tampering or unauthorized updates to the meter or hacking can't be done. A smart phone app is developed for metering and diagnostic process for having control over system and continuous monitoring is achieved to the user. 


\section{Water quality testing}

A wireless sensor network with number of sensors connected for data collection is employed in IOT environment for monitoring of water quality. A Field Programmable Gate Array (FPGA) designed board is connected to ZigBee based system through sensors and the data is fetched to cloud [32]. There are various pollutants which are the main cause for water pollution, the UVI-01 sensor, an ultraviolet proximity sensor is used to detect the water level. The ph sensor is used to monitor water quality and its temperature along its flow [33]. The data from the sensors were collected and is transferred to server using IOT [34].

Intel Galileo Gen 2 board is used for monitoring the water quality continuously and the controlling is done by programming in embedded C domain[35]. ph sensor is employed to calculate the water quality including the concentration levels of oxygen and its turbidity with respect to temperature. This data is transferred to cloud and monitoring can be done using a mobile phone as shown in figure 10.

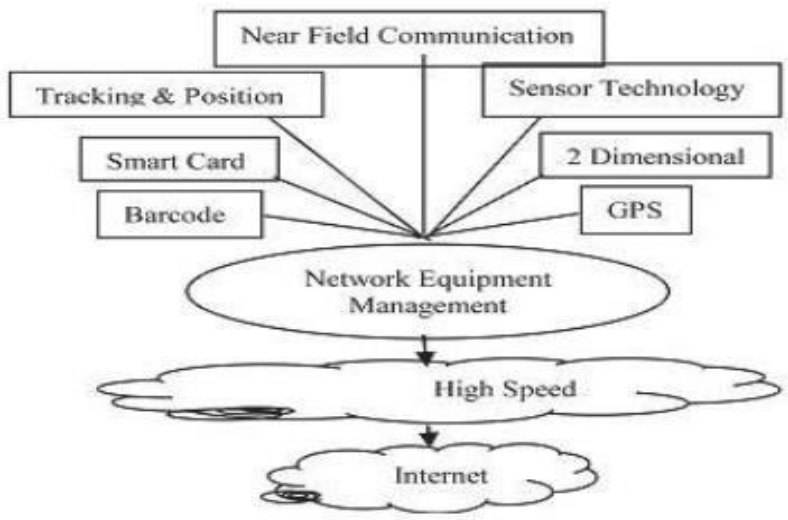

Fig. 10: Kun Hans IOT Architecture.

\section{Water distribution}

Water distribution system has been developed through human machine interface for continuous monitoring and controlling over the system. A quota is assigned to each entity (user) dynamically based on various supply and demand parameters and billing is done with such parameters. Machine learning algorithms like adaptive. Learning technique is employed for the quota system billing management with the help of IOT [36]. A low power wide area network is also known as LORA is employed for smart water grid management. The communication is done in LORA system throughout by IOT devices. The data collected from different systems which were employed at various locations to calculate the quality of water by real time data and is forwarded through email and SMS to the end user. The communication is done through LORA gate way and analysing the data is done by prediction algorithm [37].

A better flow information of a water distribution channel is analysed by various types of architectures through the data collected from the sensors and cloud [38]. The data is analysed using artificial intelligence and data analysis techniques and water management system as shown in figure 11 [39].

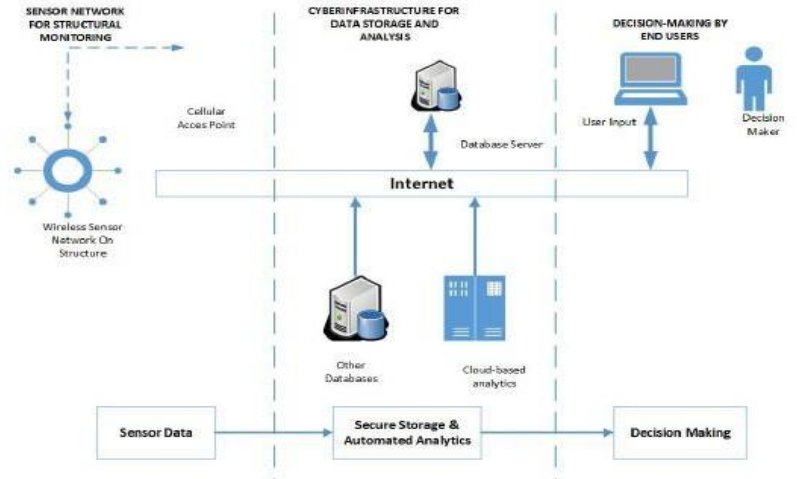

Fig. 11: IoT Platform Architecture.

\section{Agriculture}

IOT is been employed in irrigation for better water level management. Each node is mounted on a level and each level contains a variety of crop. The data is being fetched into IOT through thing speak cloud front end API. The values were collected from different types of sensors which were connected at different nodes with respect to time stamps as shown in figure 12 [40]. Variety of sensors such as temperature sensor for measuring temperature, humidity sensor for measuring humidity, I sensor for measuring light intensity, $\mathrm{M}$ sensor for soil moisture were employed to get data for better efficiency of irrigation process.

For better yielding and higher crop growth rate depends on amount of water supply. Automated control of water supply through IOT which controls the pumping motor by on and off action depending on inputs from temperature sensor, humidity sensor, soil moisture sensor from IOT based technology through a mobile phone [41]. A weather based irrigation system has been developed using Raspberry PI technology. When the humidity and temperature readings from the respective sensors cross over threshold value a signal is fed to Raspy that opens the solenoid value which decides the flow rate of water with respect to time [42].

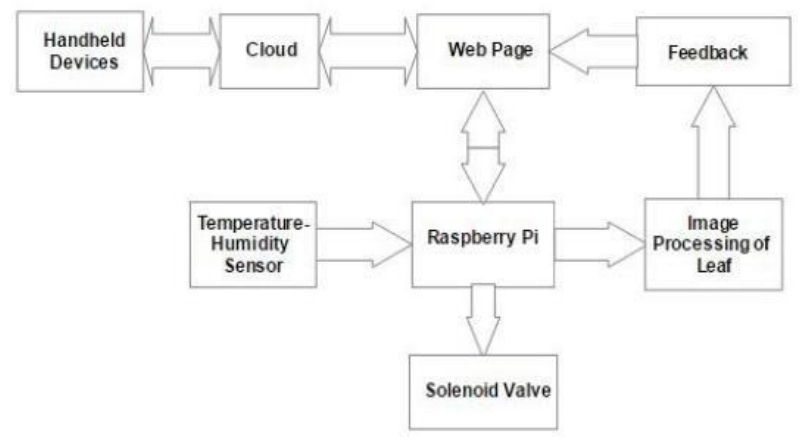

Fig. 12: Block Diagram of IOT Based Smart Irrigation System.

The reading is taken from anywhere with internet connection and controlling of valve is done through machine learning algorithm. The image taken from Raspy camera is fed to cloud and is checked for cross over operation through MAT lab software for detecting the life of plant and water is provided as per the required level for better yielding of plants as shown in figure 13 [43]. 


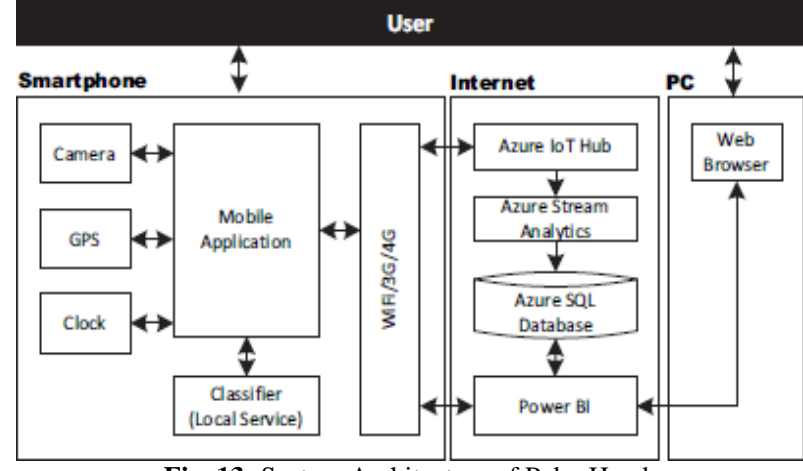

Fig. 13: System Architecture of Palm Hand.

\section{Smart metering}

Power meter has the components such as voltage transducer, a current transducer, an $\mathrm{A} / \mathrm{D}$ converter and a processor. IOT provides the user for sharing of data and information in the whole grid which includes multi hop communication so that the sensors communicate through several successive nodes and improves the grid management by including features like flexible to change conditions, prediction of energy consumption to monitor and control private security [44]. ISO/IEC/IEEE 21451 standard allows smart grid for improving its efficiency and makes easier interoperability between several sensing systems. Remote control station is developed to manage the information from different power meters by simulating the data into a central management station for performing real time operations by configuring the power network. National Instruments Single Board RIO 9626 is considered for architecture of power meter. The two modules NI 9225 and NI 9246 were employed for acquiring voltage and current signal information and are converted into digital for data processing. Xilinx spartan-6 LX45 FPGA processor is employed for processing and controlling various tasks. The embedded metrics allow the smart meter to characterize bi-directional power flow through the node. IOT provides the power meter to communicate data about their condition, position and other parameters and monitor constantly the power line temperature to estimate capacity of the power line by dynamic line rating algorithms.

Wi-Fi based energy meter using IOT with low cost has been proposed to the parameters of energy meter efficiently (load profile, demand value, energy consumption). ESP 8266, Wi-Fi module is employed for transmission of information on the website through the existing server [45].

A device has been developed to capture the image of meter to recognize its reading and that data is uploaded into cloud server for online processing [46].

Sensors like MQ6 gas sensor, DHT 11 temperature and humidity sensor, ACS712 sensor module to calculate current consumption and a micro controller board with C8051F340 chip is designed using embedded $\mathrm{C}$ for calculating the power consumption and to operate the appliances with a smart phone as shown in figure 14 [47]. The web application is designed which acts as a web server that controls Internet on things and embedded system behaves as Econtroller.

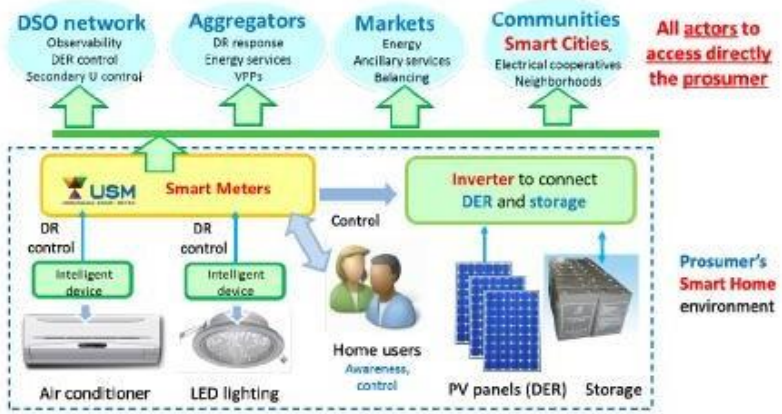

Fig. 14: Basics of Developing Smart City through Unbundled Smart Meter.
Unbundle smart meters were developed for data collecting equipment that provides various capabilities and enable variety of applications like multi-user access capability, better support development for energy market and preserving customer privacy [48].

\section{Conclusion}

This paper clearly illustrates about the importance of implementation of IoT Technology to improve the systems performance to notch up the top level system characteristics. It clearly explains the implementation of IOT technology in various and variety levels of fields and several different kinds of processing steps imbibed and involved to gear up the system performance.

\section{References}

[1] S. Vatari, A. Bakshi, and T. Thakur, "Green house by using IOT and cloud computing," 2016 IEEE Int. Conf. Recent Trends Electron. Inf. Commun. Technol. RTEICT 2016 - Proc., pp. 246- 250, 2017.

[2] R. K. Kodali, V. Jain, and S. Karagwal, "IoT based smart greenhouse," 2016 IEEE Reg. 10 Humanit. Technol. Conf., pp. 1- 6 , 2016.

[3] M. Bal and R. Abrishambaf, "A system for monitoring hand hygiene compliance based-on Internet-of-Things," Proc. IEEE Int Conf. Ind. Technol., pp. 1348-1353, 2017.

[4] I. Azimi, A. Anzanpour, A. M. Rahmani, P. Liljeberg, and T. Salakoski, "Medical warning system based on Internet of Things using fog computing," 2016 Int. Work. Big Data Inf. Secur. IWBIS 2016, pp. 19-24, 2017.

[5] J. Jusak, H. Pratikno, and V. H. Putra, "Internet of Medical Things for cardiac monitoring: Paving the way to 5G mobile networks," 2016 IEEE Int. Conf. Commun. Network, Satell. COMNETSAT 2016 - Proc., pp. 75-79, 2017.

[6] L. Enciso-Quispe, J. Delgado, H. Vivanco, E. Zelaya-Policarpo, and P. A. Quezada-Sarmiento, "Internet of things based on Android technology for people with disabilities [Internet of Things basado en Tecnología Android para personas con discapacidad]," Iber. Conf. Inf. Syst. Technol. Cist., 2017.

[7] M. Dumripatanachod and W. Piyawattanametha, "Centralized pap test diagnosis with artificial neural network and internet of things," 2016 IEEE 10th Int. Conf. Nano/Molecular Med. Eng., pp. 132135,2016

[8] S. Dhote, P. Charjan, A. Phansekar, A. Hegde, S. Joshi, and J. Joshi, "Using FPGA-SoC interface for low cost IoT based image processing," 2016 Int. Conf. Adv. Comput. Commun. Informatics, ICACCI 2016, pp. 1963-1968, 2016.

[9] A. Rupani, P. Whig, G. Sujediya, and P. Vyas, "A robust technique for image processing based on interfacing of Raspberry-Pi and FPGA using IoT," 2017 Int. Conf. Comput. Commun. Electron. COMPTELIX 2017, pp. 350-353, 2017.

[10] C. Long, Y. Cao, T. Jiang, and Q. Zhang, "Edge Computing Framework for Cooperative Video Processing in Multimedia IoT Systems," IEEE Trans. Multimed., vol. 9210, no. c, pp. 1-1, 2017.

[11] A. R. Elias, N. Golubovic, C. Krintz, and R. Wolski, "Where's The Bear?" Proc. Second Int. Conf. Internet-of-Things Des. Implement. - IoTDI'17, pp. 247-258, 2017.

[12] K. Sornalatha and V. R. Kavitha, "IoT Based Smart Museum using Bluetooth Low Energy," pp. 1-4, 2017.

[13] Y. Han, C. Lee, Y. Kim, S. Jeon, D. Seo, and I. Jung, "Smart umbrella for safety directions on Internet of Things," 2017 IEEE Int. Conf. Consum. Electron. ICCE 2017, no. 1, pp. 84-85, 2017.

[14] P. Rizwan, K. Suresh, and M. R. Babu, "Real-time smart traffic management system for smart cities by using Internet of Things and big data," 2016 Int. Conf. Emerg. Technol. Trends, pp. 1-7, 2016.

[15] M. Handte, S. Foell, S. Wagner, G. Kortuem, and P. J. Marron, “An Internet-of-Things Enabled Connected Navigation System for Urban Bus Riders," IEEE Internet Things J., vol. 3, no. 5, pp. 735$744,2016$.

[16] X. Dong et al., "Framework of future innovative urban transport," IEEE Conf. Intell. Transp. Syst. Proceedings, ITSC, pp. 19-23, 2016.

[17] A. Habib, H. Anam, W. Anwaar, H. Afaq, Y. Amin, and H. Tenhunen, "Internet-of-things based smart tracking," Proc. 2017 
Int. Conf. Commun. Comput. Digit. Syst. C-CODE 2017, pp. 44 47, 2017.

[18] F. Montori, L. Bedogni, and L. Bononi, "A Collaborative Internet of Things Architecture for Smart Cities and Environmental Monitoring," IEEE Internet Things J., vol. 4662, no. c, pp. 1-14, 2017.

[19] D. Marquez-Viloria, J. S. Botero-Valencia, and J. Villegas- Ceballos, "A low cost georeferenced air-pollution measurement system used as early warning tool," 2016 21st Symp. Signal Process. Images Artif. Vision, STSIVA 2016, pp. 1-6, 2016.

[20] V. Gokul and S. Tadepalli, "Implementation of a WiFi based plug and sense device for dedicated air pollution monitoring using IoT," Proc. 2016 Online Int. Conf. Green Eng. Technol. IC-GET 2016, 2017.

[21] G. R. C. Andrés, "CleanWiFi: The wireless network for air quality monitoring, community Internet access and environmental education in smart cities," Proc. 2016 ITU Kaleidosc. Acad. Conf. ICTs a Sustain. World, ITU WT 2016, vol. 5, 2017.

[22] Y. D. Dongyun wong, Chenglong Jiang, "Design of air quality monitoring system based on intenet of thing," p. 6, 2016.

[23] M. Firdhous, B. Sudantha, and P. Karunaratne, "IoT enabled proactive indoor air quality monitoring system for sustainable health management," Comput. Commun. Technol. (ICCCT), 2017 2nd Int. Conf., pp. 216-221, 2017.

[24] N. S. Desai and J. S. R. Alex, "IoT based air pollution monitoring and predictor system on Beagle bone black," 2017 Int. Conf. Nextgen Electron. Technol. Silicon to Software, ICNETS2 2017, pp. 367-370, 2017.

[25] S. Manna, S. S. Bhunia, and N. Mukherjee, "Vehicular Pollution Monitoring Using loT," IEEE Int. Conf. Recent Adv. Innov. Eng., pp. 1-5, 2014.

[26] R. Rushikesh and C. M. R. Sivappagari, "Development of IoT based vehicular pollution monitoring system," Proc. 2015 Int. Conf. Green Comput. Internet Things, ICGCIoT 2015, pp. 779- 783, 2016.

[27] T. Perumal, N. Sulaiman, and C. Y. Leong, "Internet of Things ( IoT ) Enabled Water Monitoring System," 2015 IEEE 4th Glob. Conf. Consum. Electron. Internet, pp. 86-87, 2015.

[28] P. Verma et al., "Towards an IoT based water management system for a campus," 2015 IEEE 1st Int. Smart Cities Conf. ISC2 2015, 2015.

[29] N. Cherukutota and S. Jadhav, "Architectural framework of smart water meter reading system in IoT environment," 2016 Int. Conf. Commun. Signal Process., vol. 400019, pp. 0791-0794, 2016.

[30] S. Wadekar, V. Vakare, R. Prajapati, S. Yadav, and V. Yadav, "Smart Water Management Using IOT," 2016 5th Int. Conf. Wirel. Networks Embed. Syst., pp. 1-4, 2016.

[31] M. Suresh, U. Muthukumar, and J. Chandapillai, "A novel smart water-meter based on IoT and smartphone app for city distribution management," TENSYMP 2017 - IEEE Int. Symp. Technol. Smart Cities, pp. 1-5, 2017.

[32] C. Z. Myint, L. Gopal, and Y. L. Aung, "WSN-based reconfigurable water quality monitoring system in IoT environment," ECTI-CON 2017 - 2017 14th Int. Conf. Electr. Eng. Comput. Telecommun. Inf. Technol., pp. 741-744, 2017.

[33] S. Athani, C. H. Tejeshwar, M. M. Patil, P. Patil, and R. Kulkarni, "Soil moisture monitoring using IoT enabled arduino sensors with neural networks for improving soil management for farmers and predict seasonal rainfall for planning future harvest in North Karnataka-India," Proc. Int. Conf. IoT Soc. Mobile, Anal. Cloud, I- SMAC 2017, pp. 43-48, 2017.

[34] H. N. Saha et al., "Pollution Control using Internet of Things ( IoT )," pp. 65-68, 2017.

[35] P. Salunke and J. Kate, "Advanced smart sensor interface in internet of things for water quality monitoring," 2017 Int. Conf. Data Manag. Anal. Innov., pp. 298-302, 2017.

[36] N. Satiya, V. Varu, A. Gadagkar, and D. Shaha, "Optimization of Water Consumption Using Dynamic Quota based Smart Water Management System," 2017 IEEE Reg. 10 Symp., no. 978-1-50906255-3/17, 2017.

[37] M. Saravanan, A. Das, and V. Iyer, "Smart water grid management using LPWAN IoT technology," GIoTS 2017 - Glob. Internet Things Summit, Proc., 2017.

[38] G. Suciu, L. Bezdedeanu, A. Vasilescu, and V. Suciu, "Unified Intelligent Water Management Using Cyberinfrastructures Based on Cloud Computing and IoT," Proc. - 2017 21st Int. Conf. Control Syst. Comput. CSCS 2017, pp. 606-611, 2017.

[39] C. Rajurkar, S. R. S. Prabaharan, and S. Muthulakshmi, "IoT based water management," Proc. Int. Conf. Nextgen Electron. Technol. Silicon to Softw., pp. 255-259, 2017.
[40] S. Salvi et al., "Cloud Based Data Analysis and Monitoring of Smart Multi-level Irrigation System Using IoT," 2017 Int. Conf. ISMAC (IoT Soc. Mobile, Anal. Cloud), pp. 752-757, 2017.

[41] I. I. Conference, G. Energy, and H. Technologies, "Intelligent Irrigation System - an Iot Based," pp. 1-5.

[42] A. J. Rau, J. Sankar, A. R. Mohan, D. Das Krishna, and J. Mathew, "IoT Based Smart Irrigation System and Nutrient Detection with Disease Analysis," pp. 3-6, 2017.

[43] M. A. Culman et al., "A Novel Application for Identification of Nutrient Deficiencies in Oil Palm Using the Internet of Things," 2017 5th IEEE Int. Conf. Mob. Cloud Comput. Serv. Eng., pp. 169 $172,2017$.

[44] R. Morello, C. De Capua, G. Fulco, and S. C. Mukhopadhyay, "A smart power meter to monitor energy flow in smart grids: The role of advanced sensing and iot in the electric grid of the future," IEEE Sens. J., vol. 17, no. 23, pp. 7828-7837, 2017.

[45] W. Hlaing, S. Thepphaeng, V. Nontaboot, N. Tangsunantham, T. Sangsuwan, and C. Pira, "Implementation of WiFi-Based single phase smart meter for internet of things (IoT)," 2017 Int. Electr. Eng. Congr. iEECON 2017, no. March, pp. 8-10, 2017.

[46] P. H. Kulkarni, P. D. Kute, and V. N. More, "IoT based data processing for automated industrial meter reader using Raspberry Pi," 2016 Int. Conf. Internet Things Appl. IOTA 2016, pp. 107-111, 2016.

[47] R. Bhilare and S. Mali, "IoT based smart home with real time Emetering using E-controller," 12th IEEE Int. Conf. Electron. Energy, Environ. Commun. Comput. Control (E3-C3), INDICON 2015, pp. 1-6, 2016.

[48] M. Sanduleac, C. L. Chimirel, M. Eremia, L. Toma, C. Cristian, and D. Stanescu, "Unleashing Smart Cities efficient and sustainable energy policies with IoT based Unbundled Smart Meters," 2016 IEEE Int. Conf. Emerg. Technol. Innov. Bus. Pract. Transform. Soc. EmergiTech 2016, no. 646184, pp. 112-117, 2016. 